\title{
Distribution of Energy Density and Optimization on the Surface of the Receiver for Parabolic Trough Solar Concentrator
}

\author{
Fei Chen, ${ }^{1}$ Ming Li, ${ }^{1}$ and Peng Zhang ${ }^{2}$ \\ ${ }^{1}$ Solar Energy Research Institute, Yunnan Normal University, Kunming 650500, China \\ ${ }^{2}$ Institute of Refrigeration and Cryogenics, MOE Key Laboratory for Power Machinery and Engineering, \\ Shanghai Jiao Tong University, Shanghai 200240, China \\ Correspondence should be addressed to Ming Li; limingse@163.com
}

Received 22 April 2014; Revised 6 September 2014; Accepted 16 September 2014

Academic Editor: Pramod H. Borse

Copyright (C) 2015 Fei Chen et al. This is an open access article distributed under the Creative Commons Attribution License, which permits unrestricted use, distribution, and reproduction in any medium, provided the original work is properly cited.

\begin{abstract}
The geometrical optics model about the offset effect of solar rays by the thickness of concentrating mirror and the diametric solar model were established. The radiant flux density on the surface of the receiver for parabolic trough solar concentrator was obtained by numerical calculation with the established models. Charge-coupled device (CCD) was used for testing gray image on the surface of the receiver for parabolic trough solar concentrator. The image was analyzed by Matlab and the radiant flux density on the surface of the receiver for parabolic trough solar concentrator was achieved. It was found that the result of the theory is consistent with that of the experiment, and the relative deviation on the focal length width was $8.7 \%$. The geometrical structure of receiver based on parabolic trough solar concentrator was optimized, a new parabolic receiver has been proposed, and it has been shown that the optimized geometrical structure of receiver was beneficial to improve the working performance of the entire system.
\end{abstract}

\section{Introduction}

The environmental issue is a significant challenge for humanity; therefore many countries are vigorously developing renewable energy technology in the world at present [1]. Solar energy has attracted much attention over the past decades with its renewable, clean, and abundant characteristics, so the concentrating solar power system (CSP) is getting more attention. Concentrating solar power system mainly consists of parabolic trough solar concentrator, linear Fresnel solar concentrator, compound parabolic solar concentrator, and solar tower, among which, the parabolic trough solar concentrator, as the most mature technology, is most widely researched and its cost is gradually reduced day by day [2-6]. At present, the parabolic trough solar concentrator, in which operating temperature is more than $400^{\circ} \mathrm{C}$, has been put into commercial operation in many countries [7] such as America, Germany, Spain, and China.

Parabolic trough solar concentrating system is mainly composed of concentrating device and thermal converting equipment. Concentrating device is the key to the entire system, and its characteristic, which was investigated by many researches, is very important for the performance of system [8]. The optical performance of half parabolic trough solar concentrator has been studied [9], and the results showed that the width $f$ focal line for half parabolic trough solar concentrator was associated with the rim angle and aperture of system. Paper [10] has studied the thermal and optical performance in the parabolic trough solar concentrator, and the results showed that the stress of concentrating mirror was large at the edge of system and the deformation of concentrating mirror was bigger than that of anywhere in the whole system, so the optical performance at the edge was not well and the system efficiency was reduced [10]. Study [11] demonstrated that the optical loss of concentrating mirror and thermal converting equipment accounted for about $20 \%$ of the total energy losses in parabolic trough solar concentrator. It was found that optical concentrating ratio was small influence by focal length in [12]. The method of measuring the error of surface shape with concentrating mirror was used to study the concentrating performance of parabolic trough solar concentrator [13]; it has been carried 
out that the performance of concentrated solar ray was reduced with the mirror surface shape as tiny change.

In the real situation, the solar rays arriving at the parabolic trough solar concentrator are partly reflected by the concentrating mirror, and the left get into concentrating mirror. However, there is rare investigation on this topic. In this study, the geometrical optics model about the offset effect of solar rays by the thickness of concentrating mirror was established. The diametric solar model was established for the convenience of calculation. The radiant flux density on the focal plane for parabolic trough solar concentrator was calculated by the established models, and the numerical result was verified by the experiment. Based on the photovoltaic and thermal system with the parabolic trough solar concentrator, the geometrical structure of receiver was optimized, and it was found that the optimized geometrical structure of receiver was beneficial to improve the working performance for whole system.

\section{The Optical Model of Concentrator Mirror}

2.1. Optical Characteristic of Concentrating Mirror. The solar rays arrive at the concentrating mirror, which are reflected, refracted, and transmitted by the concentrating mirror under the regulation of tracking device. In the actual parabolic trough solar concentrator, in order to improve the performance of the system, the material of concentrating mirror is ultraclear glass, and the thickness of concentrating mirror is not more than $5 \mathrm{~mm}$.

Next, we calculate the optic performance of the ultraclear glass. Assuming that the thickness $L$ of concentrating mirror is $1 \mathrm{~mm}, 2 \mathrm{~mm}, 3 \mathrm{~mm}, 4 \mathrm{~mm}$, and $5 \mathrm{~mm}$, respectively, the refractive index of the concentrating mirror is 1.6, and the extinction coefficient $K$ of the concentrating mirror is $4.0 \mathrm{~m}^{-1}$ [14]. When the solar rays reach the 5 types of ultraclear glass vertically, the computational formula of absorbance, reflectance, and transmittance is as follows [15]:

$$
\begin{aligned}
& r=\left[\frac{(n-1)}{(n+1)}\right]^{2}, \\
& \alpha=\left(1-e^{-K L}\right)\left[\frac{(1-r)}{\left(1-r e^{-K L}\right)}\right], \\
& \tau=\frac{\left[e^{-K L}(1-r)^{2}\right]}{\left[1-\left(r e^{-K L}\right)^{2}\right]} \\
& \rho=r\left(1+e^{-K L} \tau\right),
\end{aligned}
$$

where $r$ is surface reflectance of glass, $\alpha$ is absorbance, $\tau$ is transmittance, and $\rho$ is reflectance. The calculated results are shown in Table 1.

It can be seen in Table 1 that the absorption is very small for any thickness of glass. In general, the reflecting layer of ultraclear glass is silver, and its reflectivity is more than $95 \%$ [16]. So the main path of sunlight for parabolic trough solar concentrator is shown in Figure 1 when the solar rays arrive at the concentrating mirror. In Figure 1, WN and $V M$ are

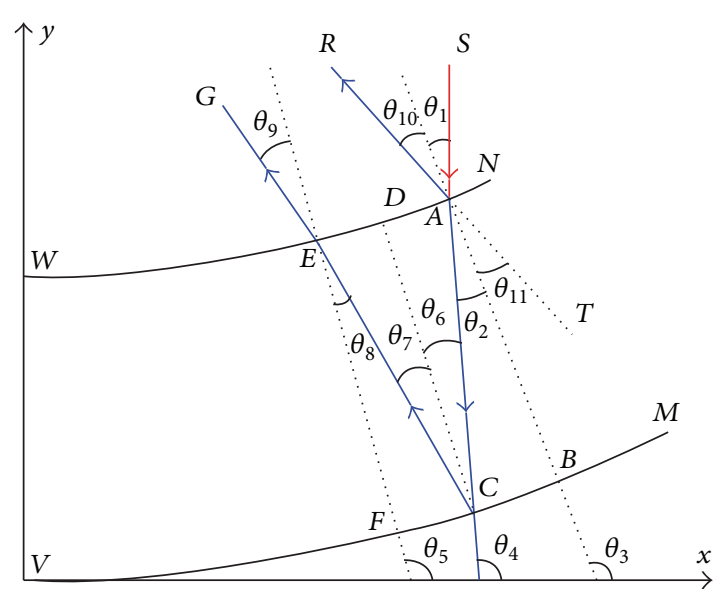

FIGURE 1: The main path of sunlight arriving at the concentrating mirror.

first reflecting surface and second silver reflecting surface, respectively. $S A$ is the incoming solar ray, $A R$ is reflected solar ray, $E G$ is the refracted solar ray, $A C$ and $C E$ are inner solar rays of ultraclear glass, and $V W$ is the thickness of ultraclear glass.

2.2. The Equation of Sunlight Path. The concentrating mirror of parabolic trough solar concentrator is a curved cylindrical mirror, which is curved by plane mirror usually. As shown in Figure 1, the plane mirror is pure bending deformation, so the top and bottom surfaces of curved plane mirror are equidistant surface by mechanics of materials. During the manufacturing process of concentrating mirror, the bottom surface of concentrating mirror is parabolic cylinder generally. The top surface is equidistant surface of bottom surface, and the distance between top surface and bottom surface of concentrating mirror is the thickness of the plane mirror.

Assuming that the parametric equation of surface $M$ in Figure 1 is

$$
\begin{aligned}
& x=4 f t, \\
& y=4 f t^{2},
\end{aligned}
$$

where $t$ is parameter and $f$ is focal length, based on the hypothesis of the equidistance surface, the parametric equation of surface $N$ is

$$
\begin{aligned}
& x=4 f t-\frac{2 \delta t}{\sqrt{1+4 t^{2}}} \\
& y=4 f t^{2}+\frac{\delta}{\sqrt{1+4 t^{2}}}
\end{aligned}
$$


TABLE 1: The absorbance, reflectance, and transmittance of ultraclear glass at different thicknesses.

\begin{tabular}{lcccr}
\hline Thickness of glass & $\alpha$ & $\tau$ & $\rho$ & $\alpha+\tau+\rho$ \\
\hline $1 \mathrm{~mm}$ & 0.003991 & 0.895186 & 0.100823 & 1.00000 \\
$2 \mathrm{~mm}$ & 0.007965 & 0.891592 & 0.100443 & 1.00000 \\
$3 \mathrm{~mm}$ & 0.011920 & 0.888013 & 0.100067 & 1.00000 \\
$4 \mathrm{~mm}$ & 0.015859 & 0.884449 & 0.099693 & 1.00000 \\
$5 \mathrm{~mm}$ & 0.019779 & 0.880899 & 0.099322 & 1.00000 \\
\hline
\end{tabular}

$\delta$ is the thickness of concentrating mirror. The refracted ray $A C$ can be gained by Snell's law:

$$
\begin{gathered}
y-\left(4 f t^{2}+\frac{\delta}{\sqrt{1+4 t^{2}}}\right) \\
=\frac{\left(4 t^{2}+u\right)}{(2 t-2 t u)\left(x-4 f t+2 \delta t / \sqrt{1+4 t^{2}}\right)}, \\
u=\sqrt{4 n^{2} t^{2}+n^{2}-4 t^{2}} .
\end{gathered}
$$

Combining formulas (2) and (4), we have

$$
\begin{aligned}
x_{C}(t) & =-\frac{2 f\left(4 t^{2}+u\right)}{(2 t u)}+\sqrt{A_{1}+A_{2} A_{3}}, \\
A_{1} & =\left[\frac{2 f\left(4 t^{2}+u\right)}{(2 t u-2 t)}\right]^{2}, \\
A_{2} & =4 f\left[4 f t^{2}+\frac{\delta}{\sqrt{1+4 t^{2}}}+\frac{\left(4 t^{2}+u\right)}{(2 t-2 t u)}\right], \\
A_{3} & =\frac{2 \delta t}{\sqrt{1+4 t^{2}}}-4 f t, \\
k_{C D} & =-\frac{2 f}{x_{C(t)}},
\end{aligned}
$$

where $x_{C(t)}$ is the parametric abscissa of point $C . k$ is slope. The ray $C E$ can be expressed as follows:

$$
\begin{aligned}
y-y_{C}(t) & =k_{C E}\left[x-x_{C}(t)\right], \\
k_{C E} & =\frac{\left(k_{A C}-2 k_{C D}-k_{C D}^{2} k_{A C}\right)}{\left(k_{C D}^{2}-2 k_{C D} k_{A C}-1\right)}, \\
k_{A C} & =\frac{\left(4 t^{2}+u\right)}{(2 t-2 t u)} .
\end{aligned}
$$

From formula (3), the general equation of surface $N$ is

$$
\begin{aligned}
x & =\left(4 f-\frac{2 \delta}{A_{4}}\right)\left(\frac{\sqrt{A_{4}^{2}-1}}{2}\right), \\
A_{4} & =\left(\frac{2 \sqrt{3(1+y / f)}}{3}\right) \cos \left(\frac{\alpha}{3}\right), \\
\alpha & =\arccos \left(-\frac{3 q \sqrt{-3 p}}{2 p^{2}}\right), \\
p & =-\left(1+\frac{y}{f}\right), \\
q & =\frac{\delta}{f} .
\end{aligned}
$$

So $y_{E}$ can be written as follows:

$$
y_{E}-y_{C}=k_{C E}\left[\left(4 f-\frac{2 \delta}{A_{4}}\right)\left(\frac{\sqrt{A_{4}^{2}-1}}{2}\right)-x_{C}\right] \text {. }
$$

Formula (11) is a transcendental equation which can be programmed for solving. So the refracted ray $E G$ can be obtained as follows:

$$
\begin{aligned}
y-y_{E} & =k_{E G}\left(\mathrm{x}-\mathrm{x}_{E}\right), \\
k_{E G} & =\frac{\left(\tan \theta_{9}+k_{E F}\right)}{\left(1-k_{E F} \tan \theta_{9}\right)}, \\
k_{E F} & =-\frac{1}{2 t_{E}}, \\
\tan \theta_{9} & =\frac{n \sin \theta_{8}}{\sqrt{1-n^{2} \sin ^{2} \theta_{8}}}, \\
\sin \theta_{8} & =\frac{\tan \theta_{8}}{\sqrt{1+\tan \theta_{8}^{2}}}, \\
\tan \theta_{8} & =\frac{\left(k_{C E}-k_{E F}\right)}{\left(1+k_{C E} k_{E F}\right)} .
\end{aligned}
$$


From Figure 1, the refracted ray $A R$ can be expressed as follows:

$$
\begin{aligned}
y & -\left(4 f t^{2}+\frac{\delta}{\sqrt{1+4 t^{2}}}\right) \\
& =\left[\frac{\left(4 t^{2}-1\right)}{4 t}\right]\left(x-4 f t+\frac{2 \delta t}{\sqrt{1+4 t^{2}}}\right) .
\end{aligned}
$$

$y$ is replaced by $f$ in formulas (12) and (18), the horizontal ordinate $x$ can be calculated when solar rays arrive on focal plane of system. The solar subtending angle is not taken into consideration and solar ray is assumed to come from the centre of the sun in formulas (12) and (18). When the solar ray comes from the other position, the $\theta_{1}$ will be replaced by $\theta_{z}$, and the value of $\theta_{z}$ will be discussed below.

\section{Diametric Solar Model}

3.1. The Numerical Calculation of Buie Model. There are many optical models of the sun, among which, Buie model is widely used. The model was established based on the observer standing on the earth and the face of the observer towards the centre of the sun. In the model, the luminance value of the sun's centre is set to be 1 , and the luminance value of other positions on the sun is the relative luminance value of center position. The advantage of the model is not affected by geographical location of the observer; the model is axial symmetry and center symmetry, and it can be written as [1720]

$$
\begin{aligned}
\Phi\left(\theta_{s}\right) & = \begin{cases}\frac{\cos \left(0.326 \theta_{s}\right)}{\cos \left(0.308 \theta_{s}\right)}, & 0 \leq \theta_{s} \leq 4.65 \mathrm{mrad}, \\
e^{k} \theta_{s}^{\gamma}, & \theta_{S}>4.65 \mathrm{mrad},\end{cases} \\
k & =0.9 \ln (13.5 \chi) \chi^{-0.3}, \\
\gamma & =2.2 \ln (0.52 \chi) \chi^{0.43}-0.1,
\end{aligned}
$$

where $\Phi\left(\theta_{s}\right)$ is factor of luminance value. $\theta_{s}$ is the polar angle of the sun; the value of $\theta_{s}$ is $16^{\prime}$ at the edge of the sun. $\chi$ is circumsolar ratio (CSR) [18]; CSR is defined as the radiant flux contained within the circumsolar region of the sky divided by the incident radiant flux from the direct beam. Under the sunny weather condition, $\chi$ is 0.05 , and the result of numerical calculation for Buie model is shown in Figure 2.

It can be seen from Figure 2 that luminance value of the sun is discontinuous in Buie model, and the luminance value of inside the sun is greater than that of outside the sun, so the outside energy of the sun is negligible in the concentrating solar system, the polar angle of the sun just only $16^{\prime}$ at the edge of the sun [21]; therefore, the range of polar angle $\theta_{z}$ can be expressed as follows:

$$
\theta_{1}-16^{\prime} \leq \theta_{z} \leq \theta_{1}+16^{\prime}
$$

3.2. Optical Performance between Receiver and Concentrating Mirror. There is a straight line on the sun's surface, which is

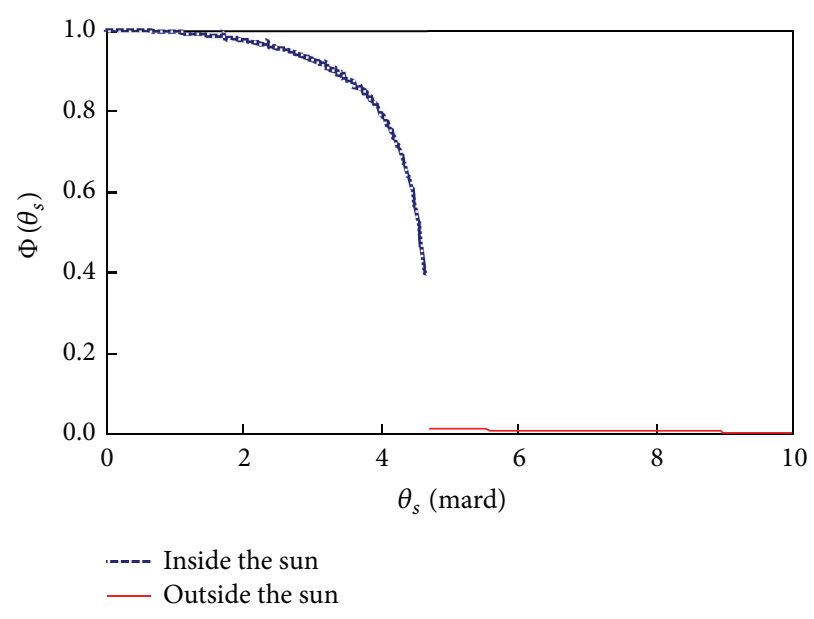

Figure 2: The calculated result of Buie model.

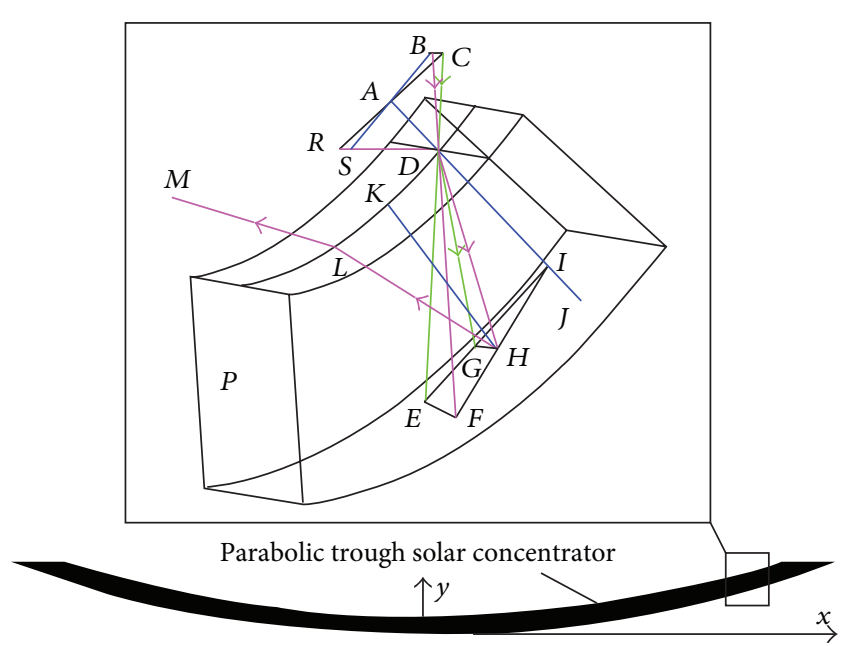

FIgURE 3: The main sunlight path for parabolic trough solar concentrator.

parallel to the generatrix of parabolic trough solar concentrator, and the rays of the straight line arrive to the concentrating mirror, the main path of sunlight arriving at the concentrating mirror as shown in Figure 3. Figure 3 shows the path of two rays, in green and pink, which are reflected and refracted; $C B$ is parallel to the generatrix of parabolic trough solar concentrator. $A J$ is the normal of concentrating mirror at point $D$. Based on the law of reflection, we have that $A B$ is equal to $A S$ and $A C$ is equal to $A R$. It can be obtained that $R S$ is parallel to $C B$. So the solar rays of every point, in the arbitrary straight line which is parallel to the generatrix of parabolic trough solar concentrator on the sun's surface, arrive to the surface of concentrating mirror. Some of them are reflected directly by concentrating mirror to the receiver; these solar rays form a straight line at surface of receiver, and the straight line is parallel to the arbitrary straight line on the sun's surface.

From Figure 3, $K H$ is normal of reflection ray, Plane $A B D$ is perpendicular to plane $B C D, A B$ is perpendicular to $B C$ and $A D$, respectively, $B D$ and $C D$ are incident rays, $D G$ 
and $D H$ are refracted rays, $G, H$ are points of intersection between $D G, D H$ and bottom surface of concentrating mirror. Assuming that $G H$ is parallel to $B C$, so it can be obtained that

$$
\begin{aligned}
B D \cos \angle A D B & =D C \cos \angle A D C, \\
D F \cos \angle F D I & =D E \cos \angle E D I, \\
\frac{B D}{D C} & =\left(\frac{A D}{\cos \angle A D B}\right)\left(\frac{\cos \angle A D C}{A D}\right)=\frac{\cos \angle A D C}{\cos \angle A D B}, \\
\frac{D F}{E C} & =\left(\frac{D I}{\cos \angle F D I}\right)\left(\frac{\cos \angle E D I}{D I}\right)=\frac{\cos \angle E D I}{\cos \angle F D I}, \\
\frac{D I \tan \angle F D I}{D I \tan \angle H D I} & =\frac{D I \tan \angle E D I}{D I \tan \angle G D I}, \\
\frac{\tan \angle A D B}{\tan \angle H D I} & =\frac{\tan \angle A D C}{\tan \angle G D I} .
\end{aligned}
$$

Obviously, formula (26) is contrary to Snell's law. So the assumption is not right, $G H$ is not parallel to $B C$. But the value of tangent function is proximately equal to sine function when the angle value is less than $5^{\circ}$. The sun subtends an angle of $32^{\prime}$, so it is high order approximate that $G H$ is parallel to $B C$. We have the conclusion that the solar rays are refracted by concentrating mirror to the receiver; these solar rays form a straight line at surface of receiver, and the straight line is highly approximatively to parallel to the arbitrary straight line on the sun's surface.

3.3. The Diametric Solar Model. The geometric relationship of Buie model is shown in Figure 4, so

$$
\begin{aligned}
& \theta_{S}=\frac{\arctan \sqrt{x^{2}+y^{2}}}{D}, \\
& 0 \leq y \leq \sqrt{R^{2}-x^{2}}
\end{aligned}
$$

where $D$ is average distance between the sun and the earth, and it is $1.495 \times 10^{11} \mathrm{~m} . R$ is radius of the sun, and it is $6.950 \times$ $10^{8} \mathrm{~m}[21]$.

Based on the optical performance of solar rays reflected and refracted by concentrating mirror, Buie model can be simplified. Buie model could be compressed with a diameter which is parallel to the generatrix of parabolic trough solar concentrator as shown in Figure 5.

So the luminance factor $I(x)$ of diametric solar model is

$$
\begin{aligned}
I(x) & =\frac{\int_{0}^{y_{0}(x)} \Phi(x, y) d y}{U} \\
U & =\int_{0}^{R} \frac{\cos [0.326 \arctan (r / D)]}{\cos [0.308 \arctan (r / D)]} d r .
\end{aligned}
$$

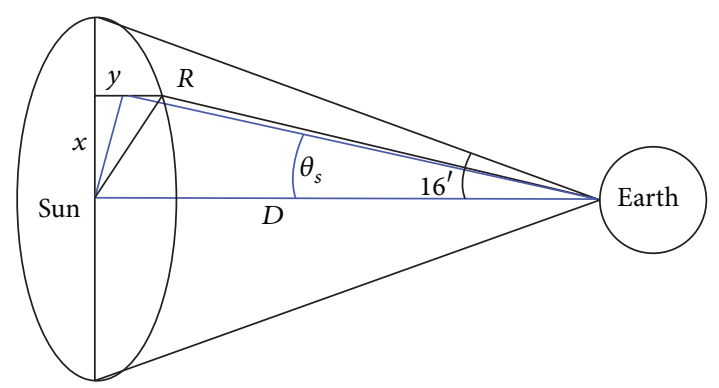

FIgURE 4: The geometric relationship of Buie model.

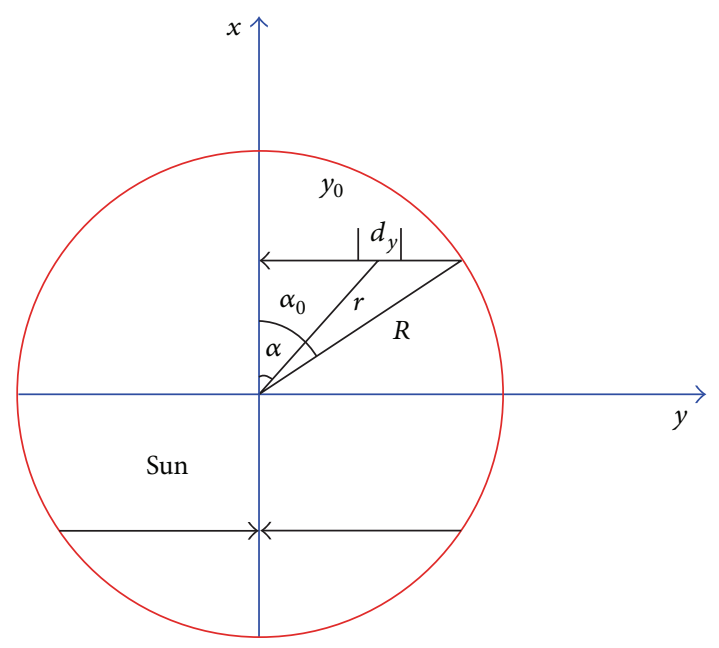

FIgURE 5: The diametral solar model.

Based on the geometric relationship from Figure 5, we have

$$
\begin{aligned}
y & =x \tan \alpha \\
d y & =x \sec ^{2} \alpha d \alpha, \\
\alpha_{0} & =\frac{\arccos x}{R} .
\end{aligned}
$$

So

$$
\begin{aligned}
I(x) & =\frac{\int_{0}^{\arccos (x / R)} L_{1} x \sec ^{2} \alpha / L_{2} d \alpha}{U}, \\
L_{1} & =\cos \left[0.326 \arctan \left(\frac{x \sec \alpha}{D}\right)\right], \\
L_{2} & =\cos \left[0.308 \arctan \left(\frac{x \sec \alpha}{D}\right)\right] .
\end{aligned}
$$

The primitive function of formula (30) is hard to find. We can use high order algebraic accuracy of the Gauss formula to calculate as follows [22]:

$$
\begin{aligned}
& \int_{0}^{b} f(x) d x \\
& \quad \approx\left(\frac{b}{2}\right)\left[f\left(\frac{b}{2}+\frac{b}{2 \sqrt{3}}\right)+f\left(\frac{b}{2}-\frac{b}{2 \sqrt{3}}\right)\right] .
\end{aligned}
$$




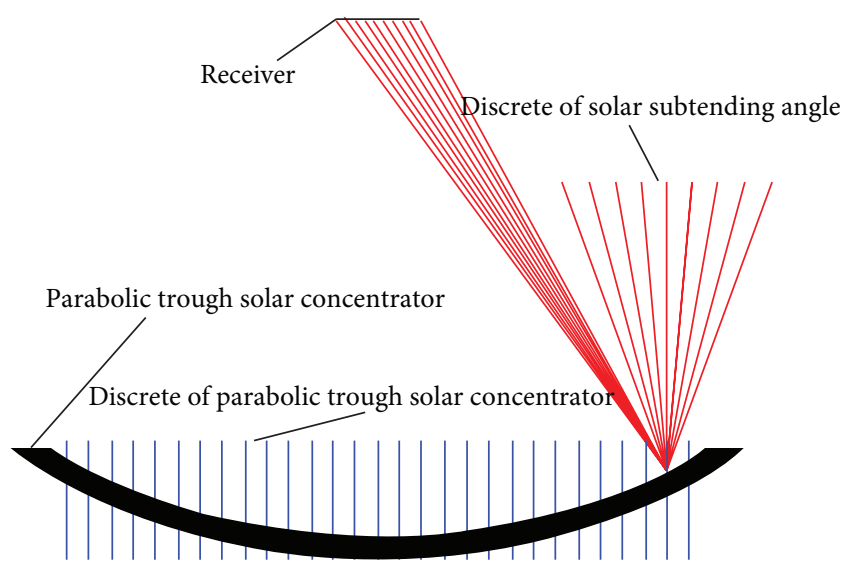

FIgURE 6: Schematic of the numerical method for energy density distribution.

\section{The Numerical Method of Diametric Solar Model}

Based on the two-dimensional parabolic trough solar concentrator, Fortran language is used to calculate the radiant flux density on the focal plane as shown in Figure 6. In the programming, the arc length of parabolic trough solar concentrator and the solar subtending angle are scattered, and the luminance factor could be obtained from the diametric solar model. The position and energy of the solar rays arrived on the surface of receiver could be calculated with formulas (12) and (18) and the radiant flux density could be gained by frequency statistics method.

The flow chart of the program is shown in Figure 7, step size of concentrating mirror and solar subtending angle are $0.5 \mathrm{~mm}$ and $0.2^{\prime}$, respectively. It can be seen in Figure 1 that $y_{E}$ is less than $y_{A}$ with geometric relationship, therefore the initial value of $y_{E}$ could take the place of $y_{A}$, and then the value of $y_{E}$ decreased time by time with step size until calculation error to meet the requirement.

\section{Experimental Verification}

The calculated results were as verified by experiment. CCD was used for testing concentrating characteristic of parabolic trough solar concentrator, and the schematic is shown in Figure 8. The CCD is put on the top surface of parabolic trough solar concentrator. CCD and computer are connected by data line. Camera lens of CCD is toward the Lambert target to make the grayscale image on the surface of Lambert target clearly visible on the computer. In order to prevent saturation of the gray images taken by CCD, a neutral attenuation was put in front of CCD lens. The specifications of the CCD are shown in Table 2.

Figure 9 is experimental system of parabolic trough solar concentrator, the aperture width of the system is $161 \mathrm{~cm}$, and focal length is $106 \mathrm{~cm}$. Concentrating mirror is ultraclear glass with a thickness of $2 \mathrm{~mm}$. The reflectivity of the concentrating mirror is $93.7 \%$, which was measured by spectrophotometer. The refractive index of concentrating mirror is 1.57 .
TABLE 2: The specifications of the CCD.

\begin{tabular}{lcc}
\hline Parameters & Specification & Unit \\
\hline Array size & $1280 \times 1024$ & Pixel \\
Pixel size & 5.2 & $\mu \mathrm{m}$ \\
Signal to noise ratio & 45 & $\mathrm{~dB}$ \\
Sensitivity & 2.1 & V/Lux-s \\
Time of exposure & 50 & $\mu \mathrm{s}$ \\
\hline
\end{tabular}

In the experiment, a two-dimensional tracking device was used in parabolic trough solar concentrator. There was a pyrheliometer near the parabolic trough solar concentrator to measure solar irradiance. The solar irradiance is measured by pyrheliometer which can track the sun automatically. The relative error of the pyrheliometer is no more than $3 \%$.

The camera was used to take the width of focal line on the surface of receiver (14 September, 2013, 12:51, Kunming, China) as shown in Figure 10, and the scale division of dividing ruler is millimeter. It can be seen in Figure 10 that the focal line width of experiment system is about $2 \mathrm{~cm}$.

Based on the experimental system, the concentrating equation of concentrating mirror and the diametric solar model were used to calculate the luminance factor of focal plane as shown in Figure 11; in order to prevent the influence of the direct irradiance, the centre luminance factor of focal plane is 1 , and the other position of the focal plane is relative luminance factor.

In order to get the radiant flux density of focal plane at different direct irradiance, we can use formula as follows:

$$
\begin{aligned}
& D_{p} I_{d}=2 \int_{0}^{x_{0}} I_{c} f(x) d x, \\
& I(x)=f(x) I_{c},
\end{aligned}
$$

where $D_{p}$ is the aperture width of system, $I_{d}$ is direct irradiance, $I_{c}$ is irradiance constant with $D_{p}$ and $I_{d}, I(x)$ is focal plane irradiance at the position of $x, f(x)$ is scale factor of relative luminance, and $x_{0}$ is the integral upper limit as shown in Figure 11.

The grayscale images of the radiation with focal plane of system and the sky were shot by CCD as shown in Figure 12; the direct irradiance of the sky was $829 \mathrm{~W} / \mathrm{m}^{2}$ measured by pyrheliometer (14 September, 2013, 12:52, Kunming, China), and Matlab was used for analyzing the gray value of the images. The average gray value of the image of direct irradiance on the sky is 3.08, and the value of irradiance is proportional to the gray level, so we have

$$
I(x)=\frac{829 H(x)}{3.08}
$$

where $H(x)$ is the gray level of image. 


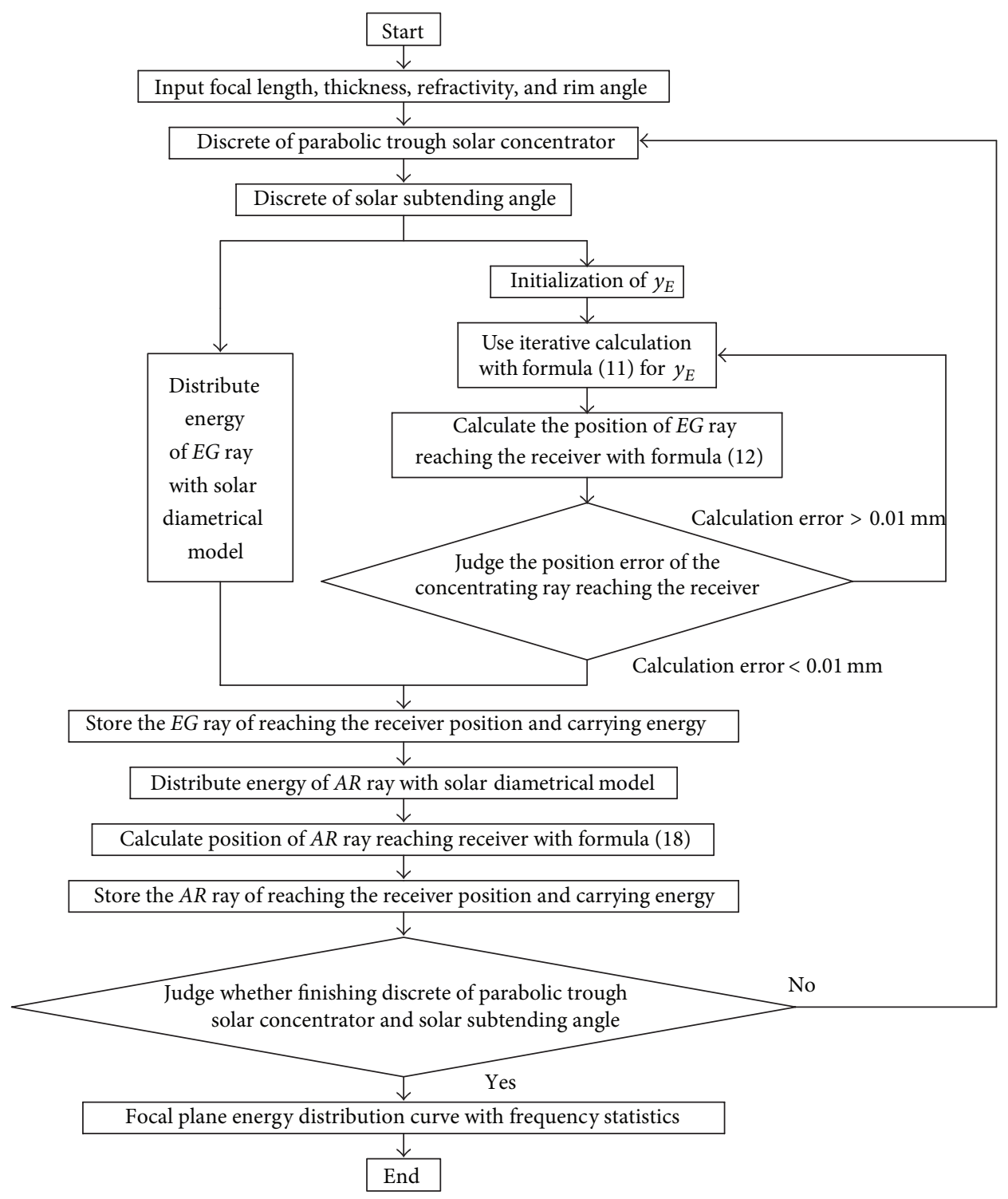

FIGURE 7: The flow chart of the numerical process.

The results of radiant flux density on the focal plane of parabolic trough solar concentrator by theoretical calculation and experimental measurement are shown in Figure 13. It can be seen in Figure 13 that the widths of focal line by calculation and experiment are $18.04 \mathrm{~mm}$ and $19.76 \mathrm{~mm}$, respectively, and the relative deviation is $8.7 \%$. The centre irradiance on focal plane of experimental result is smaller than that of numerical result. This is due to the fact that the experimental system has some machining errors, so the concentrating mirror is not standard parabolic mirror. The tracking device has certain hysteresis, and it is difficult to track the sun continuously. From Figure 11, it can be seen that the endpoint in the irradiance is zero by theoretical calculation, but the endpoint in the irradiance is not zero in the experiments. This is due to the reason that the irradiance on the surface of receiver was calculated by theory that just only considered the solar rays coming from the sun, but in the practical situation of operating parabolic trough solar concentrator, a few part of the irradiance on the surface of receiver comes from the diffuse radiation.

\section{Optimization of the Receiver}

In the solar concentrating system, the radiant flux density on the surface of concentrating solar cell is more uniform, and the operating status of $P N$ junction with solar cell is more consistent, so the loss of circulation current in solar cell is lower, the operating temperature of solar cell is lower, the temperature rise of cooling medium is much less, and the fill factor and output efficiency are much higher. It is necessary to optimize radiant flux density characteristics on the surface of the receiver. During the operating process of parabolic trough solar concentrator, the solar rays are concentrated 


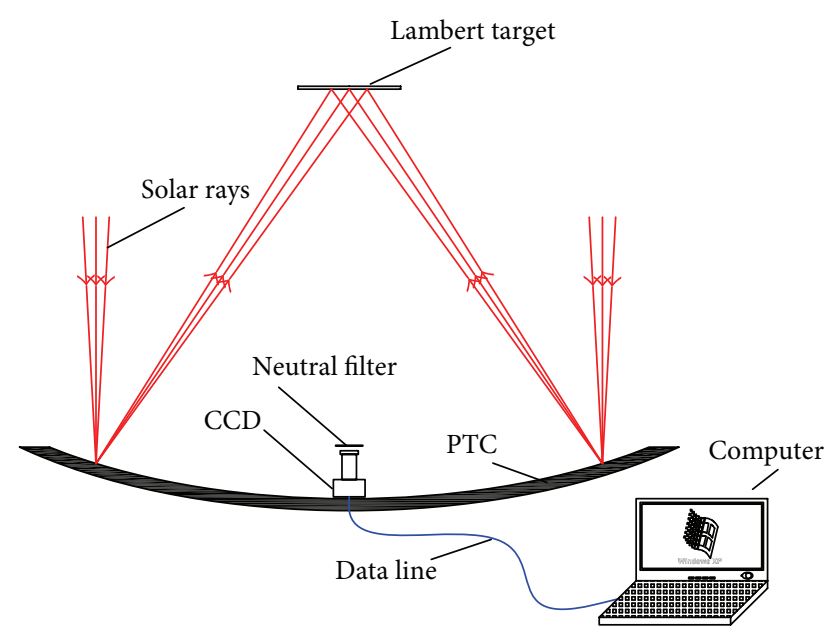

FIgURE 8: The testing schematic of CCD.

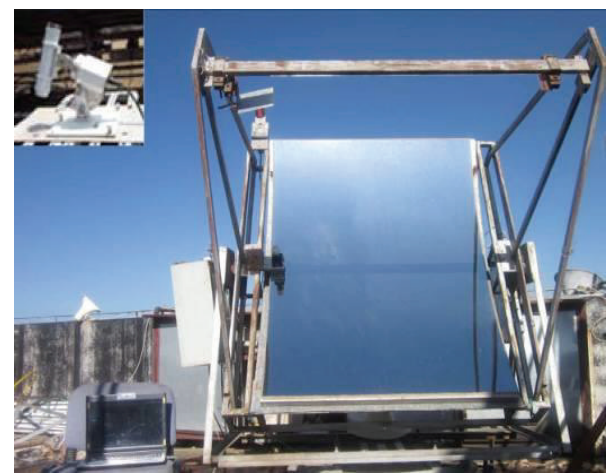

FIGURE 9: The parabolic trough solar concentrator of measuring energy density distribution.

by concentrating mirror; if the position of focal plane has receiver, the radiant energy will be converted into electricity or thermal energy; otherwise the solar rays will diverge. By geometric optical properties of parabola and the basic principle of reversible optical path, we can adopt appropriate ways to improve the uniformity of the radiant flux density on the surface of receiver; the receiver surface can be designed as parabolic and the focal point of parabolic receiver and parabolic trough solar concentrator is set to the same point as shown in Figure 14.

The radiant flux density on the surface of parabolic receiver and flat receiver is shown in Figure 15; the direct radiation is $1000 \mathrm{~W} / \mathrm{m}^{2}$, the rim angle of parabolic trough solar concentrator is $45^{\circ}$, the focal length is $1 \mathrm{~m}$, the thickness of concentrating mirror is $2 \mathrm{~mm}$, and reflectivity and refractivity of ultraclear glass are $95 \%$ and 1.6 , respectively.

It can be seen in Figure 15 that the centre energy density on the focal plane of parabolic receiver is smaller than that of plane receiver, and the variances of the radiant flux density on the focal plane of parabolic receiver and plane receiver are $7.2 \times 10^{8}$ and $5.3 \times 10^{8}$, respectively. The widths of focal line for parabolic receiver and plane receiver are $21.42 \mathrm{~mm}$

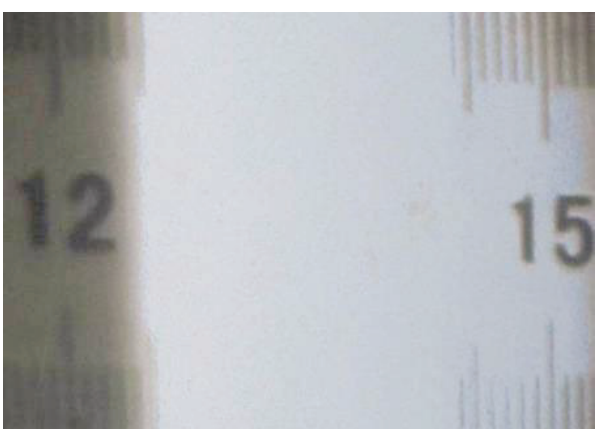

Figure 10: The width of focal line for parabolic trough solar concentrator.

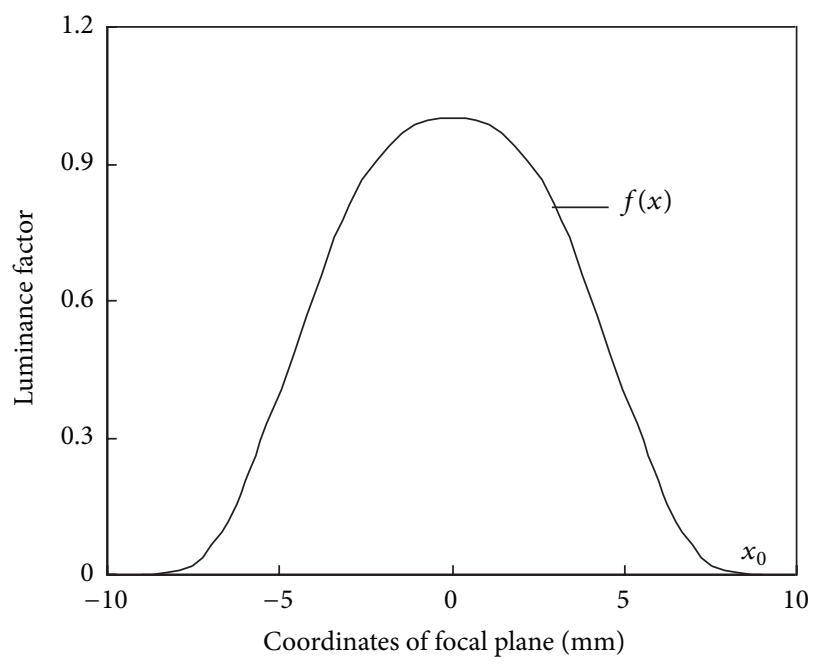

FIGURE 11: Calculated result of the luminance factor of focal plane.

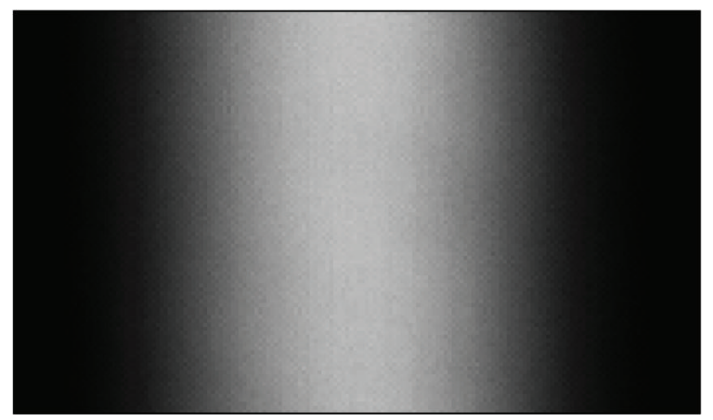

(a) The grayscale image of the focal plane of system

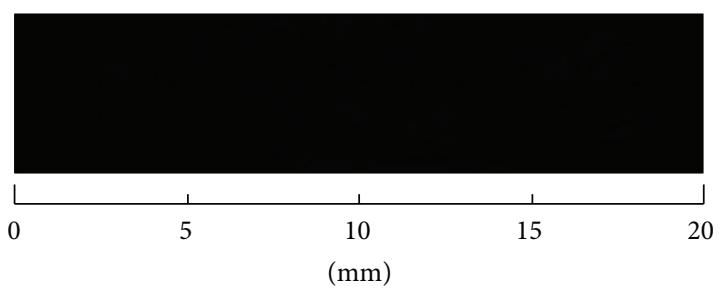

(b) The grayscale image of the direct irradiance

FIGURE 12: The grayscale image taken by CCD. 


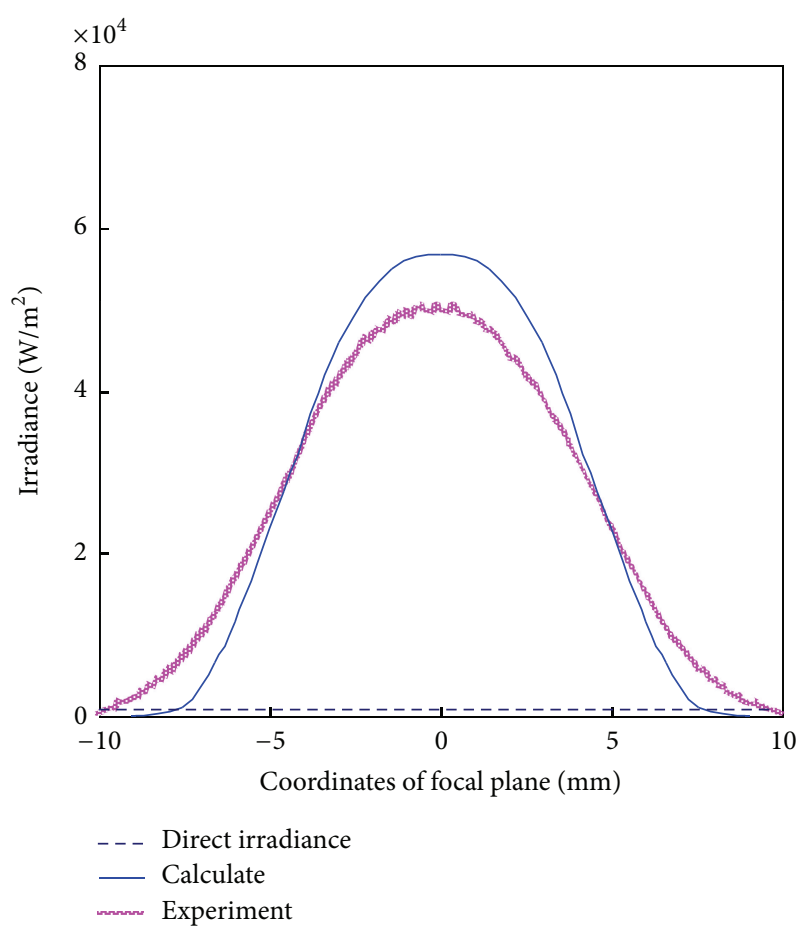

FIGURE 13: Radiant flux density of calculation and experiment.

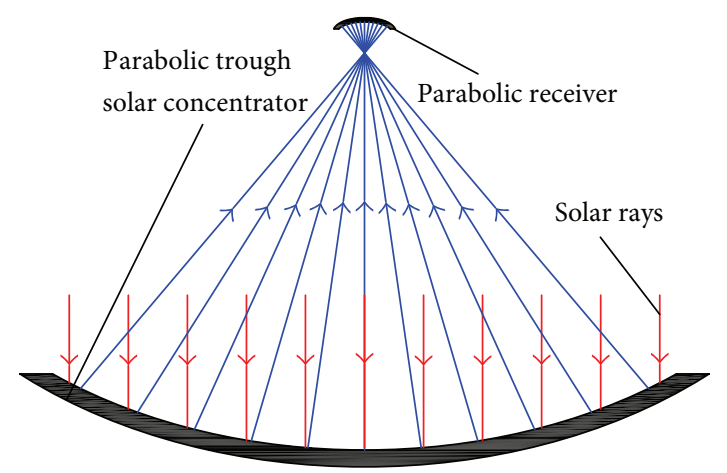

FIGURE 14: The parabola absorber is adopted on parabolic trough solar concentrator.

and $17.92 \mathrm{~mm}$, respectively. It is beneficial for operating performance of solar concentrating system.

\section{Conclusion}

The optical model of concentrator mirror and the diametric solar model were established. Based on the parabolic trough solar concentrator, the geometric construction of receiver was optimized. The main conclusion can be obtained as follows.

(1) The optical model of concentrator mirror and the diametric solar model were verified by experiment and it was found that results of theory and experiment were consistent with each other. The models could be supplied to the design for parabolic trough solar concentrator.

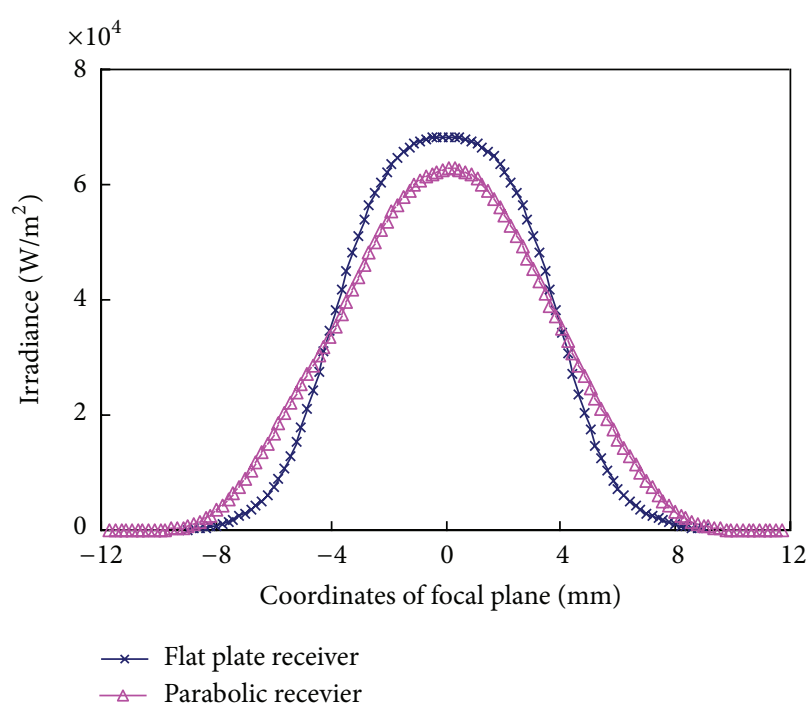

FIGURE 15: The radiant flux density on the surface of parabolic receiver and flat receiver.

(2) Based on the geometric optical properties of parabola and the principle of reversible optical path, a new parabolic receiver has been proposed. It was found that the optimized and designed parabolic receiver was beneficial to improve the characteristic of concentrating solar cells.

\section{Conflict of Interests}

The authors declare that there is no conflict of interests regarding the publication of this paper.

\section{Acknowledgments}

The present study was supported by National Natural Science Foundation, China (Grant no. U1137605), the Program of Changjiang Scholars and Innovative Research Team in Ministry of Education, China (Grant no. IRT0979), and the National and international scientific and technological Cooperation projects, China (Grant no. 2011DFA60460).

\section{References}

[1] J. Wei, B. Huang, P. Wang et al., "Photocatalytic properties of nitrogen-doped $\mathrm{Bi}_{12}$ TiO20 synthesized by urea addition sol-gel method," International Journal of Photoenergy, vol. 2012, Article ID 135132, 8 pages, 2012.

[2] F.-Q. Wang, Y. Shuai, and H.-P. Tan, "Thermal analysis of solar cavity type receiver," Journal of Engineering Thermophysics, vol. 32, no. 5, pp. 843-846, 2011.

[3] C. S. Solanki, C. S. Sangani, D. Gunashekar, and G. Antony, "Enhanced heat dissipation of V-trough PV modules for better performance," Solar Energy Materials and Solar Cells, vol. 92, no. 12, pp. 1634-1638, 2008.

[4] T. Tao, Z. Hongfei, H. Kaiyan, and A. Mayere, "A new trough solar concentrator and its performance analysis," Solar Energy, vol. 85, no. 1, pp. 198-207, 2011. 
[5] H. Zhao, H. Liu, L. Jing et al., "Discrete spectral local measurement method for testing solar concentrators," International Journal of Photoenergy, vol. 2012, Article ID 290474, 8 pages, 2012.

[6] A. Fernández-García, E. Zarza, L. Valenzuela, and M. Pérez, "Parabolic-trough solar collectors and their applications," Renewable and Sustainable Energy Reviews, vol. 14, no. 7, pp. 1695-1721, 2010.

[7] Y.-L. He, J. Xiao, Z.-D. Cheng, and Y.-B. Tao, "A MCRT and FVM coupled simulation method for energy conversion process in parabolic trough solar collector," Renewable Energy, vol. 36, no. 3, pp. 976-985, 2011.

[8] G. Gong, X. Huang, J. Wang, and M. Hao, "An optimized model and test of the China's first high temperature parabolic trough solar receiver," Solar Energy, vol. 84, no. 12, pp. 2230-2245, 2010.

[9] S. L. Jiang, Fundamental Theory and Experimental Study of Reflective Concentrating Solar Energy Utilization, University of Science and Technoligy of China, Heifei, China, 2009.

[10] J. Coventry, A Solar Concentrating Photovoltaic/Thermal Collector, Australian National University, Canberra, Australia, 2004.

[11] Y. H. Cui, Z. H. Bei, and X. Zhao, "Research on the heat loss of parabolic trough solar collector field," Renewable Energy Resources, vol. 28, no. 5, pp. 5-9, 2010.

[12] Y. Shuai, X.-F. Zhang, and H.-P. Tan, "Simulation for concentrating characteristic of parabolic solar collector system," Journal of Engineering Thermophysics, vol. 27, no. 3, pp. 484-486, 2006.

[13] A. Maccari and M. Montecchi, "An optical profilometer for the characterisation of parabolic trough solar concentrators," Solar Energy, vol. 81, no. 2, pp. 185-194, 2007.

[14] H. F. Zhang, The Principle and Simulation of Solar Thermal Utilization, Northwestern Polytechnical University Press, Xi'an, China, 2007.

[15] A. Duffie and A. Beckman, Solar Engineering of Thermal Process, Wiley-Interscience, Madison, Wis, US, 1980.

[16] J.-L. Du, D.-W. Tang, T. Li, and G.-P. Su, "Design and experiment research of a solar simulator in Dish/Stirling Solar Power Generation System," Journal of Engineering Thermophysics, vol. 31, no. 11, pp. 1883-1885, 2010.

[17] C. M. Xu, M. Li, X. Ji, and X. Luo, "Frequency statistics analysis for energy-flux-density distribution on focal plane of parabolic trough solar concentrators," Acta Optica Sinica, vol. 33, no. 4, Article ID 0408001, 2013.

[18] D. Buie, A. G. Monger, and C. J. Dey, "Sunshape distributions for terrestrial solar simulations," Solar Energy, vol. 74, no. 2, pp. 113-122, 2003.

[19] Y. Liu, J. Dai, Z. Lang, and C. Xin, "Finite-element analysis for flux distribution on focal plane of rotating parabolic concentrators," Acta Optica Sinica, vol. 27, no. 10, pp. 1775-1778, 2007.

[20] J. M. Dai and Y. Liu, "The study of flux distribution on focal plane in parabolic trough concentrators," Acta Optica Sinica, vol. 29, no. 9, pp. 1096-1100, 2008.

[21] J. A. Duffie and W. A. Beckman, Solar Engineering of Thermal Processes, John Wiley \& Sons, Hoboken, NJ, USA, 4th edition, 2013.

[22] J. F. Jiang, L. J. Hu, and J. Tang, Numerical Analysis and MATLAB Experiment, Science Press, Beijing, China, 2004. 

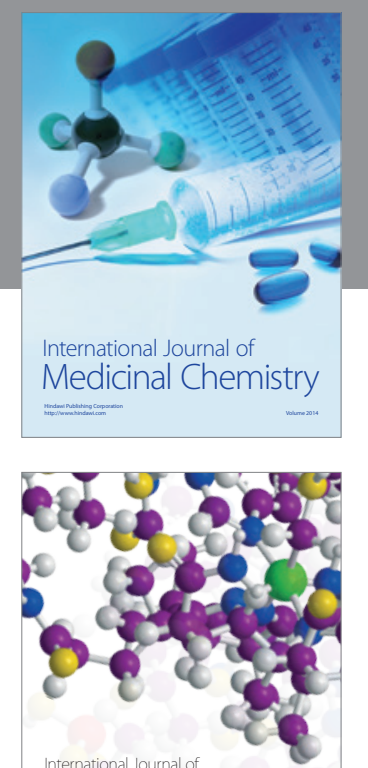

\section{Carbohydrate} Chemistry

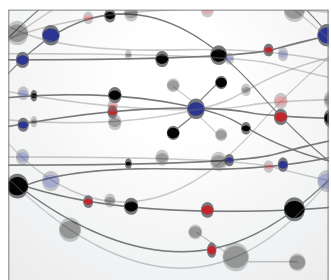

The Scientific World Journal
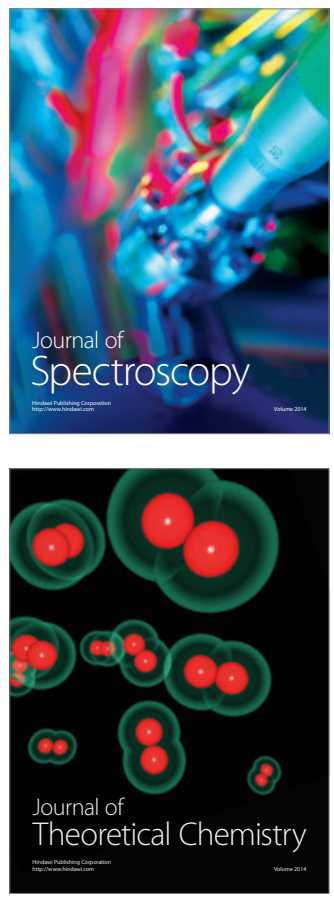
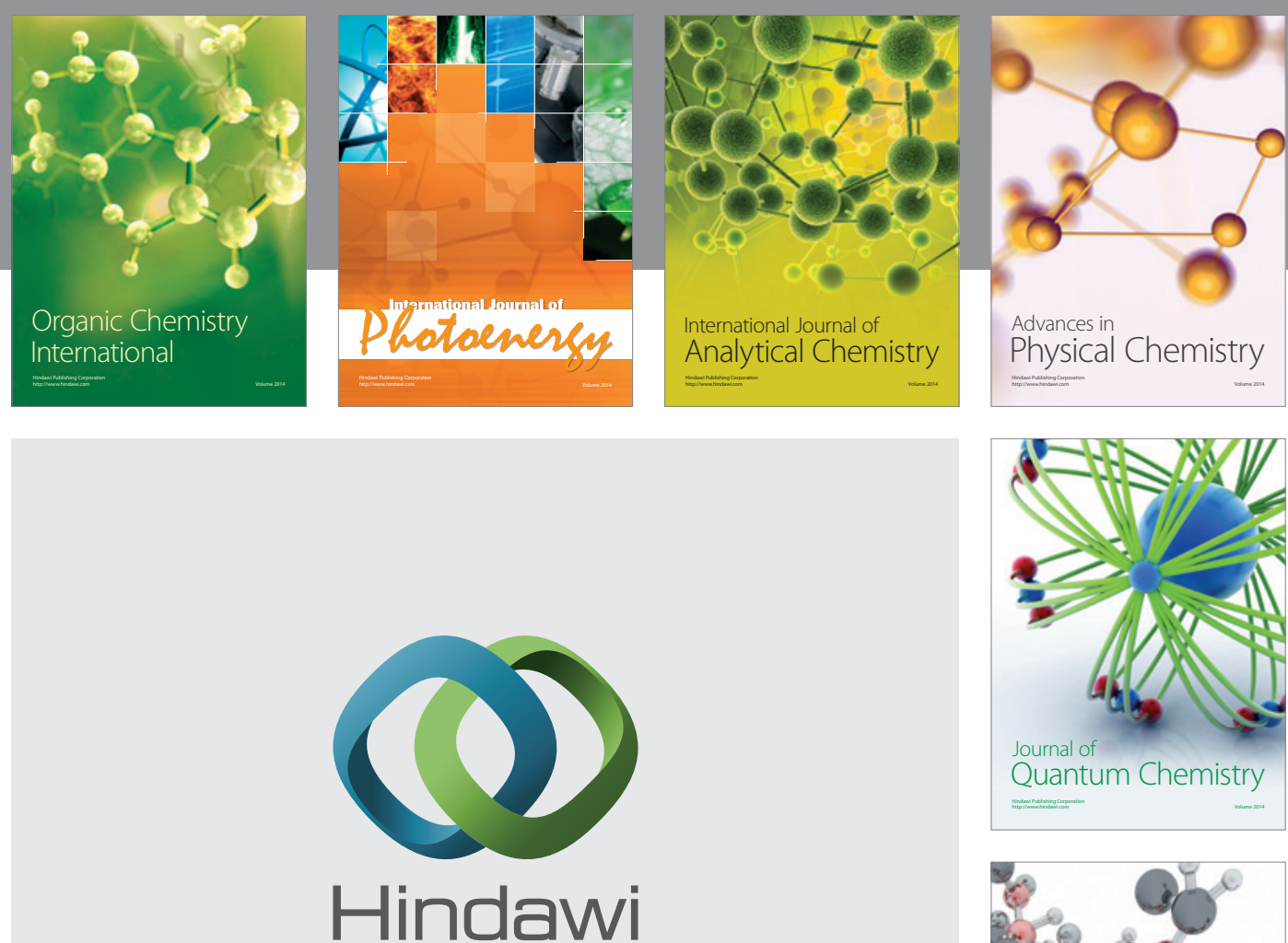

Submit your manuscripts at

http://www.hindawi.com

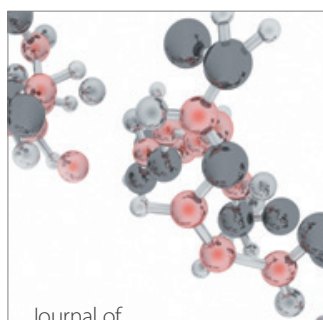

Analytical Methods

in Chemistry

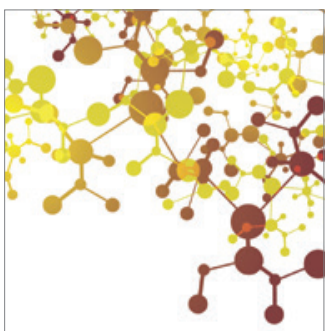

Journal of

Applied Chemistry

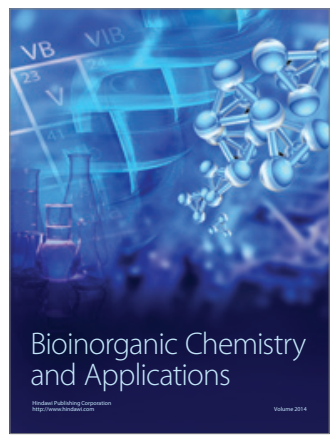

Inorganic Chemistry
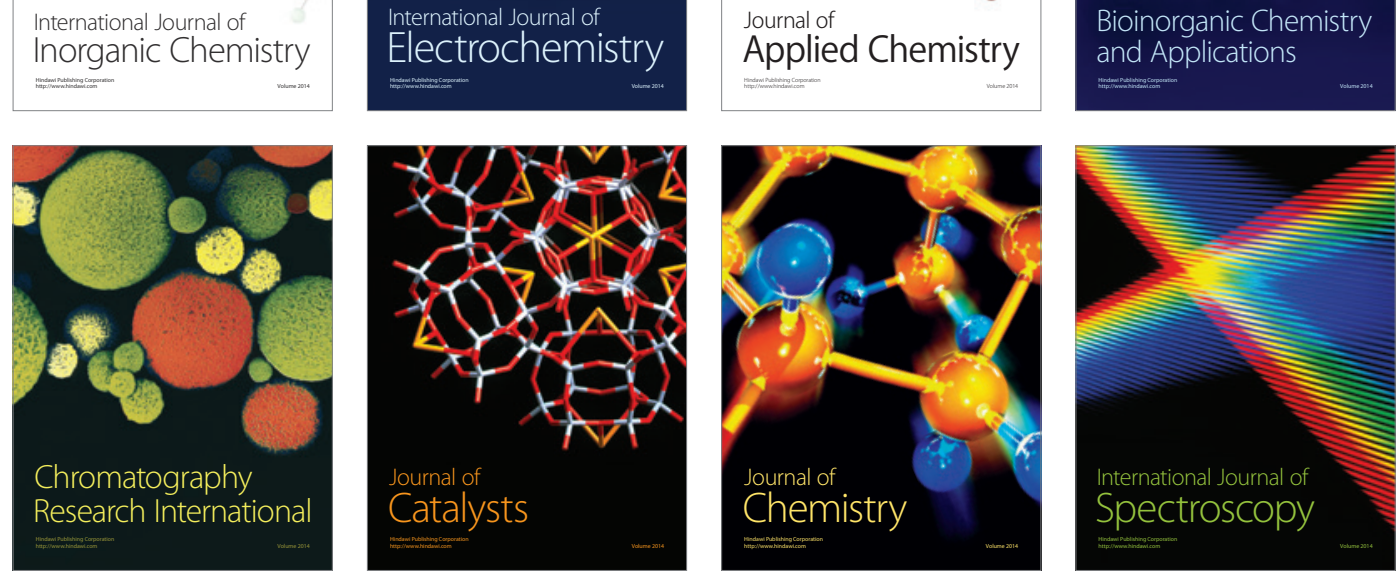